\title{
BLACK WIDOW SPIDERS AT THE PRAIRIE WILDLIFE INTERPRETATION CENTRE
}

\section{DOUGLAS ADAMS, 401-108th Street, Saskatoon, Saskatchewan. S7N 1R1}

Five years ago (1980) I saw my first Black Widow Spider in an abandoned gopher hole, located $1 \mathrm{~km}$ from the site of the Prairie Wildlife Interpretation Centre. The original occupants had dug into the side of a gently sloping hill, sparsely covered by Spear Grass and Buffalo Grass. Strands of silk radiated downwards from the top lip of the hole. The shiny, black spider was clinging to the underside of the irregular-shaped web. It's $13 \mathrm{~mm}$ body was suspended between long, slender, outstretched legs. The spider's crimson red hour-glass marking glowed in the light of the late evening sun.

The Black Widow presented the staff at the centre with a rare opportunity to observe the habits of this much maligned and poorly understood spider. I did my best to stop by and see the 8-legged celebrity whenever I was scheduled to work outdoors. On 18 July I was forced to make an urgent visit to the burrow.

A colleague had removed 2 of 4 silk sacs hanging in the spider's web, and unaware that the web belonged to the Black Widow or that the globular, creamcoloured sacs were egg cases, had carried the sacs back to the centre to have them identified.

The larger case, $1.5 \mathrm{~cm}$ in diameter, was home for at least 100 spiderlings. The immature spiders were about to undergo their first molt before leaving the egg case. The smaller egg case, $1.0 \mathrm{~cm}$ across, protected a large number of small, white eggs.

The honour of reuniting the spider and her offspring was bestowed on me. The female was hiding under the roof of the hole while the two remaining egg cases were left unguarded near the top of the web. Balancing the sacs on the end of a stick, I placed them several inches below the pair hanging in the web. I sat down to wait for the spider to appear from her hiding place. The wait was not long. Sixty seconds after the sacs were in place, the female descended. She quickly scooped up the returned egg cases, carried them up the web and then deposited them alongside the other cases.

I was astonished by how quickly the spider reacted. In only 60 seconds, the female identified and located the egg cases. Finding the sacs would have been simple enough. The spider would have received tactile messages from two sources: the pressure of the sacs on the web; and, the movement of the spiderlings inside the egg case. But how did the spider know the sacs were egg cases? Association by sight can be ruled out because Black Widows have poor eyesight. A possible explanation is that air-borne chemicals may have been released from the damaged silk cases. The female detected the chemicals and took appropriate action to retrieve her lost eggs and spiderlings.

By the end of August of 1980, one of the offspring had inherited mother's estate. On the same hillside, sibling spiders had discovered other ground squirrel holes suitable for winter occupancy. A large percentage of the new generation would not survive the cold winter months ahead. But a few individuals would awaken in the spring to complete their life cycle. 




Black Widow Spider

Doug Adams 